\title{
Management and outcome of spontaneous subaponeurotic fluid collections in infants: the Hospital for Sick Children experience and review of the literature
}

\author{
Shelly Wang, MD, ${ }^{1,2}$ James Drake, MB BCh, MSc, FRCSC, ${ }^{1,3}$ and \\ Abhaya V. Kulkarni, MD, PhD, FRCSC1,3,4 \\ ${ }^{1}$ Division of Neurosurgery, Department of Surgery, University of Toronto, Ontario, Canada; ${ }^{2}$ Departments of Biostatistics and \\ Epidemiology, Harvard T. H. Chan School of Public Health, Boston, Massachusetts; and 'Department of Surgery, Division of \\ Neurosurgery, and ${ }^{4}$ Pediatric Gamma Knife Program, Hospital for Sick Children, Toronto, Ontario, Canada
}

\begin{abstract}
OBJECTIVE Spontaneous subaponeurotic fluid collection (SSFC) is an uncommon and newly described entity of unknown etiology, observed in infants less than 1 year of age. The authors report on series of infants who presented to the Hospital for Sick Children (HSC) with SSFC, focusing on the natural history of this condition.

METHODS Data from the Hospital for Sick Children were retrospectively reviewed for the period between January 2004 and June 2015. Patient age and sex, birth history, medical history, laboratory findings, and symptoms were reviewed. SSFC location, imaging characteristics, management, and outcome were also analyzed. A MEDLINE and Embase literature search was performed on the condition, yielding previously reported cases of SSFC in the English language.

RESULTS Nine cases involving patients who presented with SSFC during the study period were identified. The patients were 4 male and 5 female infants (age range 5 weeks to 11 months). All cases of SSFC developed spontaneously over a period of days, and the infants had no history of injuries, trauma, or hair manipulation in the immediate period preceding the development of the subgaleal collections. Six patients underwent remote forceps- or vacuum-assisted instrumented births, although none of the patients developed scalp collections or skin discoloration immediately after birth. All of the cases were managed conservatively on an outpatient ( 6 cases) or inpatient ( 3 cases) basis. In 1 case, the size of the fluid collection fluctuated over 4 months, but in all of the cases, the collections resolved spontaneously without structural or infectious complications.
\end{abstract}

CONCLUSIONS This is the largest series describing SSFC to date and summarizes 9 cases managed at a large academic neurosurgical center. Although the specific pathophysiology of SSFC remains unknown, in some cases the condition may be associated with a remote history of instrumented delivery. SSFC occurs spontaneously without immediate preceding trauma, and an extensive hematology or child abuse workup is not necessary. A conservative approach with outpatient follow-up is advocated.

http://thejns.org/doi/abs/10.3171/2016.4.PEDS1641

KEY WORDS collection; pediatric; scalp; spontaneous; subgaleal; subaponeurotic

$\mathrm{N}$ EONATAL scalp collections are common, especially among infants with prolonged or instrumented births and cesarean births. The differential diagnosis for scalp collections in newborns include cephalohematoma, caput succedeneum, and subgaleal hematoma (SGH), which usually present immediately after delivery. Less is known about the condition of delayed spontaneous subaponeurotic fluid collection (SSFC), which is described as a soft, fluctuant, and mobile collection that crosses su- ture lines, presenting in well-appearing and hemodynamically stable infants less than 1 year of age, with no immediate preceding history of trauma. ${ }^{14}$ The pathophysiology and etiology of SSFC is unknown, but the presence of a spontaneous scalp collection without a volunteered history of trauma often raises suspicion of child abuse and sparks a series of investigations. It is important, therefore, to recognize and distinguish this condition, since the occurrence is spontaneous, and the natural history is one of

ABBREVIATIONS EVOH = extraventricular obstructive hydrocephalus; FFE = fast field echo; FSE = fetal scalp electrode; $\mathrm{HSC}=\mathrm{Hospital}$ for Sick Children; $\mathrm{SGH}=$ subgaleal hematoma; SSFC = spontaneous subaponeurotic fluid collection; TFE = turbo field echo; TSE = turbo spin echo.

SUBMITTED January 21, 2016. ACCEPTED April 21, 2016.

INCLUDE WHEN CITING Published online July 8, 2016; DOI: 10.3171/2016.4.PEDS1641. 
resolution without intervention. Herein, we present our experience with SSFC at the Hospital for Sick Children (HSC) in Toronto.

\section{Methods}

The case records of a prospectively maintained neurosurgery database at HSC were reviewed to identify cases of SSFC presenting between January 2004 and June 2015. Medical records and imaging studies were retrospectively reviewed for the following information: patient age, sex, birth history, medical history, laboratory findings, symptoms, SSFC location, imaging characteristics, management, and outcome. Approval for this study was received from the HSC Research Ethics Board.

An English language literature review was carried out by searching MEDLINE and Embase, using the search terms "spontaneous subaponeurotic collection", "spontaneous subgaleal collection", and "spontaneous scalp collection." Relevant articles were reviewed by 2 authors (S.W. and A.V.K.) for inclusion and data were extracted by the first author.

\section{Results}

Nine cases of SSFC in infants less than 1 year of age were identified for the time period specified. The patients were 4 male and 5 female infants, ranging from 5 weeks to 11 months of age at presentation (Table 1).

\section{Past History}

Six infants had a history of vacuum or forceps use during delivery (unsuccessful in 2 cases), 3 infants were delivered by cesarean section, and 1 infant experienced prolonged birth. However, none of the infants displayed evidence of scalp trauma, subgaleal collection, or skin discoloration immediately after birth. Two patients had metopic craniosynostosis, and one of these 2 patients had 2q37 deletion. None of the infants had a history of surgery or interventions. Furthermore, there was no family or personal history of coagulopathy, spontaneous fluid collection or hematoma formation in other areas, or traumatic injuries.

\section{Clinical Presentation}

All 9 patients presented with a fluctuant and soft subgaleal collection, which began spontaneously and increased over a period of days. No injuries, trauma, or hair pulling immediately preceded the development of the collection, and the cases were presumed to be spontaneous. Four patients presented to the emergency department due to rapid accumulation of the collection ( 3 of the 4 patients were then admitted as inpatients for investigations and observation). The rest of the infants were referred to the neurosurgical clinic as outpatients by their pediatricians.

The locations of the subgaleal collections included the vertex (in 4 cases), occipital (2), frontal (2), and frontoparietal (1) areas. All infants were hemodynamically stable, afebrile, and in no acute distress. In each case, clinical examination of the local area revealed a nontender, compressible, and mobile lesion. There was no evidence of trauma, and the overlying scalp showed no discoloration or bruising. No local compressive symptoms were displayed, and the infants were neurologically intact.

\section{Imaging}

All of the infants received an ultrasonographic examination or CT scan to investigate the composition and extension of the SSFC. Ultrasound frequently displayed a hypodense and anechoic fluid collection that was mobile and crossed suture lines. In some cases, there was

TABLE 1. The HSC case series of 9 infants with development of SSFC

\begin{tabular}{|c|c|c|c|c|c|c|c|}
\hline $\begin{array}{l}\text { Case } \\
\text { No. }\end{array}$ & $\begin{array}{l}\text { Pt Age, } \\
\text { Sex }\end{array}$ & Location & $\begin{array}{c}\text { Delivery } \\
\text { Complications }\end{array}$ & PMH & Investigations & Management & Outcome \\
\hline 1 & 5 wks, $M$ & $\begin{array}{l}\text { Anterior } \\
\quad \text { fontanelle }\end{array}$ & $\begin{array}{l}\text { Forceps-assisted, } \\
\text { C-section }\end{array}$ & None & US & Outpatient follow-up & $\begin{array}{l}\text { Resolved spontaneously } \\
\text { (in } 2 \text { wks) }\end{array}$ \\
\hline 2 & 6 wks, F & Rt occipital & $\begin{array}{l}\text { Vacuum-assisted, } \\
\text { C-section }\end{array}$ & None & CT & $\begin{array}{l}\text { Inpatient admission } \\
\text { (for } 1 \text { day) }\end{array}$ & Resolved spontaneously \\
\hline 3 & 2 mos, $\mathrm{M}$ & Vertex & Vacuum-assisted & $\begin{array}{l}\text { Metopic craniosynos- } \\
\text { tosis }\end{array}$ & CT & Outpatient follow-up & $\begin{array}{l}\text { Resolved spontaneously } \\
\quad \text { (in } 3 \text { mos) }\end{array}$ \\
\hline 4 & $3 \mathrm{mos}, \mathrm{M}$ & Rt occipital & Vacuum-assisted & Macrocephaly, EVOH & X-ray, CT, MRI & $\begin{array}{l}\text { Inpatient admission } \\
\text { (for } 4 \text { days) }\end{array}$ & $\begin{array}{l}\text { Resolved spontaneously } \\
\text { (in } 5 \text { wks) }\end{array}$ \\
\hline 5 & $3 \mathrm{mos}, \mathrm{M}$ & Vertex & Vacuum-assisted & None & US, CT & Outpatient follow-up & $\begin{array}{l}\text { Resolved spontaneously } \\
\text { (in } 5 \text { mos) }\end{array}$ \\
\hline 6 & $4 \mathrm{mos}, \mathrm{F}$ & Vertex & C-section & $\begin{array}{l}\text { Metopic craniosynosto- } \\
\text { sis, } 2 \text { q37 deletion }\end{array}$ & CT & Outpatient follow-up & Resolved spontaneously \\
\hline 7 & $6 \mathrm{mos}, \mathrm{F}$ & $\begin{array}{l}\text { Lt fronto- } \\
\text { parietal }\end{array}$ & Vacuum-assisted & None & CT & Outpatient follow-up & $\begin{array}{l}\text { Resolved spontaneously } \\
\quad \text { (in } 2 \text { mos) }\end{array}$ \\
\hline 8 & 10 mos, $\mathrm{F}$ & Vertex & Prolonged labor & None & US & Outpatient follow-up & $\begin{array}{l}\text { Waxed/waned for } 4 \text { mos, } \\
\text { then resolved }\end{array}$ \\
\hline 9 & 11 mos, F & Bifrontal & NVD & None & X-ray, US, MRI & $\begin{array}{l}\text { Inpatient admission } \\
\quad \text { (for } 3 \text { days) }\end{array}$ & $\begin{array}{l}\text { Increased in size during } \\
\text { 3-day admission, then } \\
\text { resolved spontaneously }\end{array}$ \\
\hline
\end{tabular}

$\mathrm{EVOH}=$ extraventricular obstructive hydrocephalus; $\mathrm{NVD}=$ normal vaginal delivery; $\mathrm{PMH}=$ past medical history; $\mathrm{pt}$ = patient; US = ultrasound 

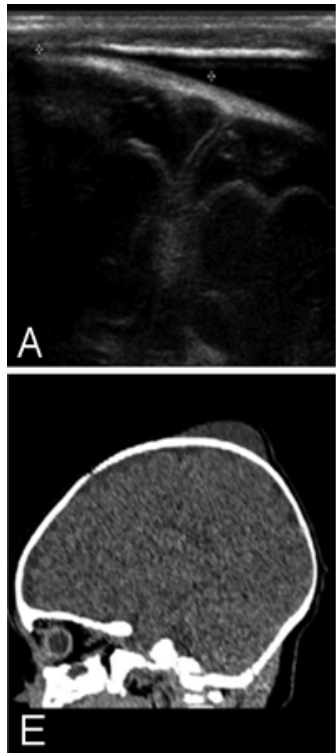
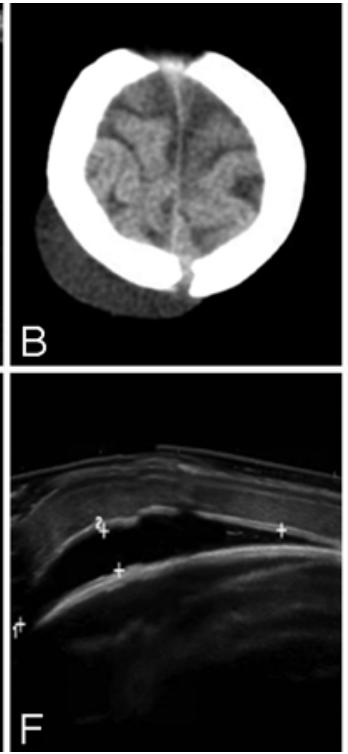
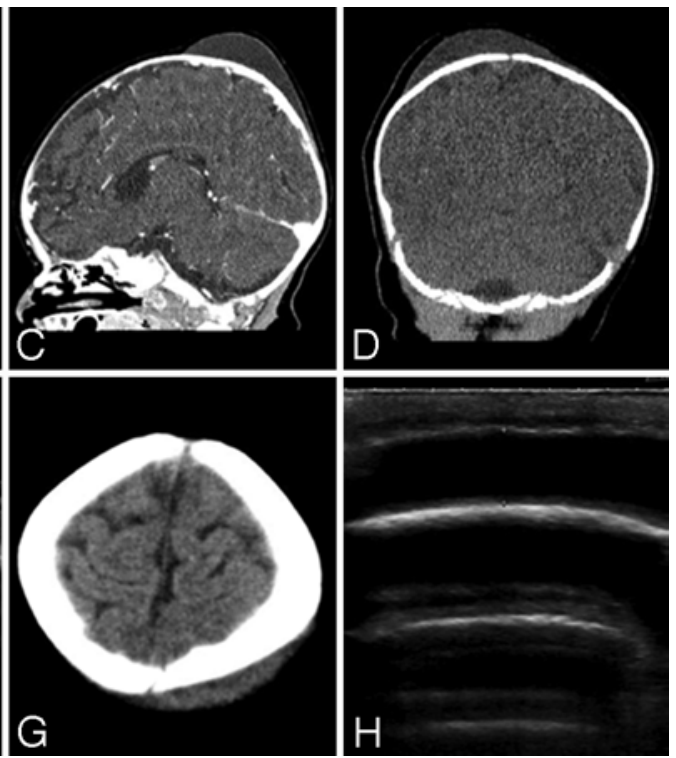

FIG. 1. Images obtained in patients with SSFC in the HSC case series. A: Case 1, ultrasound image. B: Case 2, axial CT image. C: Case 2, contrast-enhanced sagittal CT image. D: Case 3, coronal CT image. E: Case 3, sagittal CT image. F: Case 5, ultrasound image. G: Case 6, axial CT image. H: Case 8, ultrasound image.

evidence of mild skin thickening and edema overlying the collection. CT showed a relatively homogeneous hypodense cystic collection, sometimes associated with minor external skull bony changes. There was no evidence of any skull fracture or intracranial abnormality in any of the patients (Fig. 1). Two patients with more extensive subgaleal collections (Cases 4 and 9) also underwent MRI. The patient in Case 4 had findings of macrocephaly (head circumference greater than 98th percentile) and extraventricular obstructive hydrocephalus $(\mathrm{EVOH})$ in addition to the subgaleal fluid collection. There was no enhancement with contrast and no evidence of blood products on gradient echo MRI sequences (Fig. 2). The most unusual case was Case 9, which involved an 11-month-old girl with a large bifrontal subgaleal collection without traumatic history. This case was somewhat atypical due to the patient's older age and the very extensive nature of her collection, which continued to expand in size during her inpatient admission. She underwent extensive investigations, including ultrasonography, CT, and MRI. Again, ultrasound showed a hypodense and anechoic lesion and CT displayed a hypodense collection. The MRI showed a thick $15-\mathrm{mm}$ subgaleal collection with intermediate $\mathrm{T} 1$ signal, fluid/fluid level, areas of low T2 signal, and rim enhancement. Furthermore, gradient echo MRI sequences, including T1 TFE (turbo field echo), T2 FFE (fast field echo), and T2 TSE (turbo spin echo), revealed the presence of hemosiderin staining and blood products (Fig. 3). No intracranial extension was observed and no abnormalities were appreciated on vascular imaging.

\section{Laboratory Investigations}

One patient, a 5-week-old male (Case 1), presented with a low hemoglobin level of $89 \mathrm{~g} / \mathrm{L}$. The biochemistry, hematology, and coagulation profiles were universally unremarkable in all other children, including the patient in Case 9, in whom a hematology consult with full coagulopathy workup (Factor VIII, Factor VIII inhibitor, von Willebrand factor, Factor XIII, Factor XIII activity) showed no abnormalities and no injuries or signs of abuse were found following a SCAN (suspected child abuse and neglect) investigation.

\section{Management and Outcome}

In all 9 cases in this series, the SSFCs resolved within weeks to months. All of the cases were managed conser-
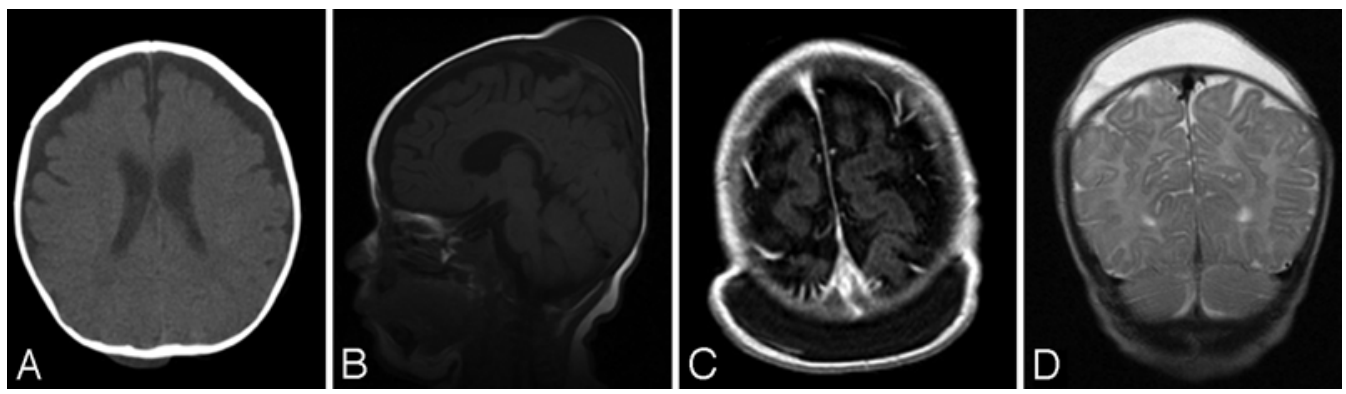

FIG. 2. Images obtained in Case 4 (3-month-old male with occipital SSFC). A: Axial noncontrast CT image. B: Sagittal T1weighted MR image. C: Axial Gd-enhanced T1-weighted MR image. D: Coronal T2-weighted TSE MR image. 

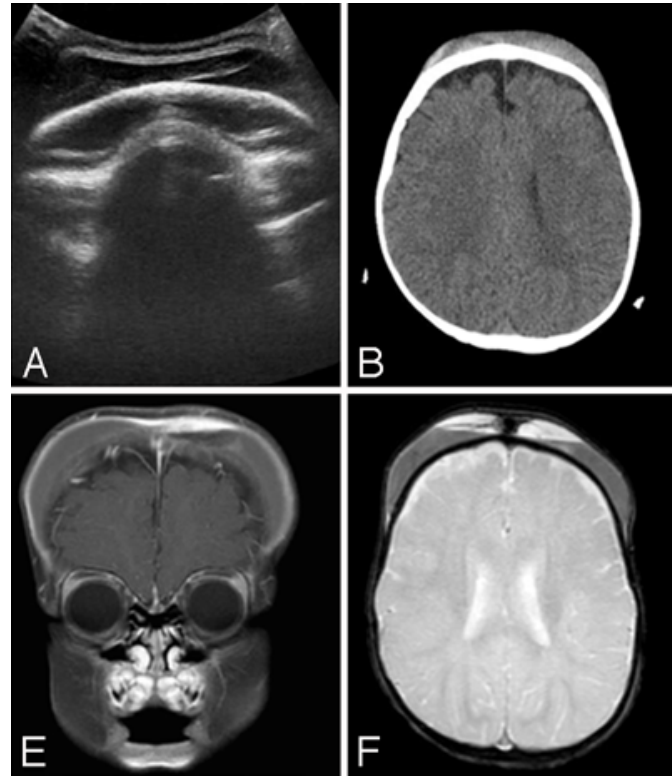
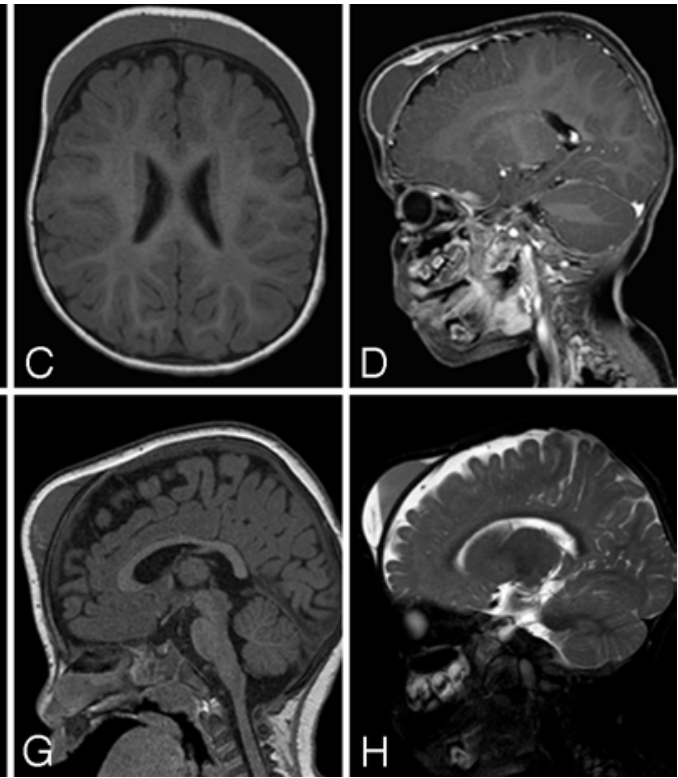

FIG. 3. Images obtained in Case 9 (11-month-old female with rapidly expanding bifrontal SSFC) demonstrating extensive 15-mm subgaleal collection, with fluid/fluid level and rim-enhancement. A: Frontal ultrasound image. B: Axial noncontrast CT image. C: Axial T1-weighted MR image. D: Sagittal Gd-enhanced T1-weighted MR image. E: Coronal Gd-enhanced T1-weighted MR image. F: Axial T2-weighted FFE MR image. G: Sagittal TI-weighted TFE MR image. H: Sagittal T2-weighted TSE MR image.

vatively. Three of the patients were admitted as inpatients for investigations, consultations, and monitoring. The inpatient stays were universally stable. None of the patients in our series underwent any intervention-including fluid sampling, needle aspiration, or compressive wrapping.

None of the patients had any recurrence during the follow-up period, which ranged from 2 weeks to 5 months.

\section{Literature Review}

We identified 7 articles describing a total of 21 infants ranging from 2 to 18 weeks of age a $^{4-6,10,11,14}$ (Table 2). Nineteen children had a history of complicated birth, including prolonged delivery, fetal scalp electrode (FSE) monitoring, forceps- or vacuum-assisted instrumented delivery, or cesarean delivery. In 1 infant, SSFC developed shortly after lumbar puncture for febrile workup. ${ }^{6}$ In all other cases, SSFC developed spontaneously over a period of days, manifesting as a fluctuant and soft collection without local compressive or neurological symptoms. The majority of the cases were managed conservatively, although 6 infants underwent fluid aspiration. Needle aspiration was frequently followed by rapid re-accumulation of the collection and did not seem to hasten recovery. The cases of SSFC reported in the literature resolved within weeks to months, with no long-term sequelae.

\section{Discussion}

We have presented the largest series of SSFC reported in literature, which features 2 older infants (10 months and 11 months of age) with very unusual presentations of this condition. Furthermore, our case series highlights the benign nature of this condition, as an entity that forms and resolves spontaneously. The results of extensive investigations (MRI with vascular studies, extended hematology workup, or full suspected child abuse investigation) are unremarkable and such investigations are frequently unwarranted.

The scalp is divided into 5 layers: skin, superficial fascia, galea aponeurotica, loose areolar tissue, and periosteum. Subaponeurotic fluid collections occur between the epicranial aponeurosis of the scalp and the periosteum. This potential space extends forward to the orbital margins, backward to the nuchal ridge, and laterally to the temporal fascia. Unlike a cephalohematoma, which is restricted by the subperiosteal space and its attachments at the cranial sutures, subaponeurotic fluid crosses suture lines and may extend anteriorly to the orbital ridges and posteriorly to the nape of the neck.

An SSFC presents as a soft, ill-defined, fluctuant, and mobile scalp swelling that is not limited by suture lines. The main differential diagnosis is spontaneous subgaleal hematoma (SGH) or a resolving hematoma mixed in with seroma content. SGHs are well-known entities, most commonly occurring in the perinatal period. Early reviews of perinatal SGHs demonstrated that they were associated with fetal macrosomia, prolonged labor, prematurity, positional dystocia, and most commonly, with vacuum-assisted deliveries (in $48 \%$ to $89 \%$ of the cases). ${ }^{2,9}$ In older infants, spontaneous SGH can result from very minor trauma, hair manipulation, coagulopathy, or vascular abnormalities. SGHs usually develop within 1 day of injury, although delayed presentation have been reported 6 weeks later. ${ }^{1}$ Spontaneous SGH and SSFC can be differentiated through clinical history, presentation, and imaging.

The etiology and pathophysiology of SSFC are unknown, although some theories have been proposed. In the literature, 19 of the 21 infants with this condition had a history of complicated or instrumented delivery. Our HSC data support this association, as 8 of the 9 infants 
TABLE 2. Summary of 21 previously reported pediatric cases of SSFC

\begin{tabular}{|c|c|c|c|c|c|}
\hline Authors \& Year & Pt Age, Sex & Risk Factors & Imaging & Management & Management \& Outcome \\
\hline \multirow[t]{6}{*}{ Hopkins et al., 2002} & 18 wks, NR & $\begin{array}{l}\text { Vacuum-assisted delivery, resolved cepha- } \\
\text { lohematoma }\end{array}$ & X-ray, US & Conservative & $\begin{array}{l}\text { Resolved spontaneously } \\
\text { (in } 24 \text { wks) }\end{array}$ \\
\hline & 13 wks, NR & $\begin{array}{l}\text { Failed vacuum- \& forceps-assisted delivery, } \\
\text { C-section, resolved caput succedaneum }\end{array}$ & X-ray, US & $\begin{array}{l}\text { Aspiration } \times 2 \text {, com- } \\
\text { pression bonnet }\end{array}$ & Resolved (in 12 wks) \\
\hline & 3 wks, NR & Vacuum-assisted delivery & X-ray, US & Conservative & $\begin{array}{l}\text { Resolved spontaneously } \\
\text { (in } 4 \text { wks) }\end{array}$ \\
\hline & 3 wks, NR & NVD & X-ray, US & Conservative & $\begin{array}{l}\text { Resolved spontaneously } \\
\text { (in } 2 \text { wks) }\end{array}$ \\
\hline & 8 wks, NR & NVD & X-ray, US & Conservative & $\begin{array}{l}\text { Resolved spontaneously } \\
\text { (in } 2 \text { wks) }\end{array}$ \\
\hline & 6 wks, NR & Vacuum- \& forceps-assisted delivery & X-ray, US & Conservative & $\begin{array}{l}\text { Resolved spontaneously } \\
\text { (in } 9 \text { wks) }\end{array}$ \\
\hline \multirow[t]{5}{*}{ Schoberer et al., 2008} & 7 wks, NR & Vacuum-assisted delivery & US, CT, MRI & Aspiration $\times 2$ & Resolved* \\
\hline & 8 wks, NR & C-section, failed cephalic version & US & Aspiration & Resolved* \\
\hline & 8 wks, NR & Vacuum-assisted delivery & US, CT & Aspiration & Resolved* \\
\hline & 8 wks, NR & Vacuum-assisted delivery & US, CT & Conservative & Resolved* \\
\hline & 8 wks, NR & Vacuum-assisted delivery & US & Conservative & Resolved* \\
\hline \multirow[t]{3}{*}{ Petraglia et al., 2010} & 9 wks, NR & Vacuum-assisted delivery, FSE monitoring & X-ray +/- CT & Conservative & $\begin{array}{l}\text { Resolved spontaneously } \\
\text { (in } 5 \mathrm{wks} \text { ) }\end{array}$ \\
\hline & 5 wks, NR & FSE monitoring, C-section & X-ray +/- CT & Conservative & $\begin{array}{l}\text { Resolved spontaneously } \\
\text { (in } 6 \text { wks) }\end{array}$ \\
\hline & 5 wks, NR & FSE monitoring, C-section & X-ray +/- CT & Conservative & $\begin{array}{l}\text { Resolved spontaneously } \\
\text { (in } 5 \mathrm{wks} \text { ) }\end{array}$ \\
\hline \multirow[t]{4}{*}{ Vaibhav et al., 2010} & 2 wks, F & C-section & None & Conservative & Resolved spontaneously \\
\hline & 4 wks, M & Vacuum- \& forceps-assisted, C-section & None & Conservative & Resolved spontaneously \\
\hline & 8 wks, M & C-section & X-ray, US, MRI & Conservative & Resolved spontaneously \\
\hline & 14 wks, M & C-section & & Conservative & Resolved spontaneously \\
\hline $\begin{array}{l}\text { McAloon \& McCabe, } \\
2013\end{array}$ & 8 wks, NR & Instrumentation, C-section & X-ray & Aspiration & Resolved \\
\hline Medows et al., 2014 & 14 wks, M & $\begin{array}{l}\text { C-section, recent spinal tap (for fever } \\
\text { workup) }\end{array}$ & CT & Conservative & $\begin{array}{l}\text { Resolved spontaneously } \\
\text { (in } 5 \text { wks) }\end{array}$ \\
\hline Roy \& Magdum, 2014 & 8 wks, M & Forceps-assisted, FSE monitoring, C-section & CT, MRI & Aspiration & Resolved (in wks) \\
\hline
\end{tabular}

FSE = fetal scalp electrode; NR = not reported.

* All 5 cases resolved within 1-5 months (reported as a range).

in our case series experienced prolonged delivery, forceps or vacuum instrumentation, or cesarean section. In the 6 cases in the literature in which needle aspiration and fluid analysis were performed, the fluid appeared serosanguineous and was sterile on microbiology analysis. In 1 case no further biochemical analysis was performed; ${ }^{4}$ in another, the aspirate suggested seroma content; ${ }^{5}$ and in another, the aspirate suggested CSF content. ${ }^{10,11}$ Additionally, the case series by Schoberer et al. ${ }^{11}$ featured 3 children with comprehensive aspirate profiles: in all 3 cases, testing was positive for $\beta 2$ transferrin, with $\beta$-trace protein levels of $11.6-50 \mathrm{mg} / \mathrm{L}$, protein levels of $12-25 \mathrm{~g} / \mathrm{L}, \beta$-trace protein aspirate/serum ratio of 10.5-38.7, and leukocyte levels of 44-1220/ $\mu$ l. The presence of CSF content in select cases led authors to speculate that SSFC may be a delayed presentation of self-limited CSF fistula in young infants, possibly as a result of an FSE needle penetrating of the infant's thin skull. The association of FSE and CSF leakage has been supported by previous studies. ${ }^{37,12,13} \mathrm{An}$ - other case study described a 14-week old male infant who developed SSFC a day after lumbar puncture for febrile workup, raising the possible role of CSF dynamic changes in its formation. ${ }^{6}$ SSFC may be a delayed manifestation of remote injury, as in the case of 2 infants with instrumented deliveries and perinatal caput succedaneum or cephalohematoma that had resolved weeks prior to SSFC development. ${ }^{4}$ This theory may be supported by another case involving an older child, a 7-year-old girl who developed a parietal SSFC 1 month following a minor injury to the eyebrow. ${ }^{4}$ Lastly, SSFC and SGH may represent conditions along a continuum rather than 2 distinct entities. Evidence of hemosiderin on imaging has been reported in literature, and this observation is supported by the MRI findings in Case 9 in our series. Perinatal or spontaneous SGHs may not be recognized immediately, due to their solid composition. With the normal restorative process as the clot becomes aqueous, the collection may become more recognizable and concerning. 
Regardless of etiology and risk factors, all of the SSFC cases in the literature have been uncomplicated, with spontaneous resolution. Our HSC case series further supports this benign natural history; with the exception of 1 infant who underwent a few episodes of regression and re-accumulation of the subgaleal collection over 4 months (Case 8), the rest of the cases resolved spontaneously over weeks to months. In the literature, fluid aspiration of SSFC is followed by rapid re-accumulation over hours. Needle aspiration followed by application of a compression dressing does not appear to hasten resolution of the collection and is not recommended for uncomplicated cases of SSFC. Furthermore, unless there is clinical suspicion of infection, fluid analysis of the collection is noncontributory.

Increasing knowledge of this benign but rare entity will benefit physicians (pediatricians, emergency department doctors, and neurosurgeons) and parents. A recently published article highlights the experiences of 69 families of infants with rare scalp collections, by gathering their experiences through a disease-specific blog. Some of the themes that emerged from the research included lack of provider awareness, concern about unnecessary diagnostic procedures, and parental anxiety regarding accusations of child abuse.${ }^{15}$ Hopefully, as increased physician awareness regarding this rare entity emerges, there will be improved understanding of the benign and self-resolving nature of SSFC, and a reduction in unnecessary diagnostic testing, child abuse investigations, inpatient admissions, and interventions.

\section{Conclusions}

SSFC is a relatively uncommon, but benign, entity. Laboratory and imaging studies can be considered to rule out differential diagnoses of traumatic injury, spontaneous $\mathrm{SGH}$, or other scalp lesions, but if the clinical diagnosis of SSFC is clear, the condition does not warrant extensive workup or follow-up investigations. SSFCs self-resolve without intervention and needle aspiration does not hasten resolution.

\section{References}

1. Agrawal A, Pratap A, Sundas A, Tiwari A: Delayed extensive subgaleal hematoma following minor head injury. Pediatric Oncall 3:Art \#44, 2006

2. Chadwick LM, Pemberton PJ, Kurinczuk JJ: Neonatal subgaleal haematoma: associated risk factors, complications and outcome. J Paediatr Child Health 32:228-232, 1996

3. Goodlin RC, Harrod JR: Complications of fetal spiral electrodes. Lancet 1:559, 1973

4. Hopkins RE, Inward C, Chambers T, Grier D: Sub-aponeurotic fluid collections in infancy. Clin Radiol 57:114-116, 2002

5. McAloon J, McCabe J: An unusual swelling on an infant's head. Arch Dis Child Fetal Neonatal Ed 98:410, 2013
6. Medows M, Mohammad Nijres B: Delayed subaponeurotic (subgaleal) fluid collection. BMJ Case Rep 2014:bcr2013203457, 2014 [Erratum in BMJ Case Rep 2015:bcr2013203457corr1, 2015]

7. Nieburg P, Gross SJ: Cerebrospinal fluid leak in a neonate associated with fetal scalp electrode monitoring. Am J Obstet Gynecol 147:839-840, 1983

8. Petraglia AL, Moravan MJ, Marky AH, Silberstein HJ: Delayed sub-aponeurotic fluid collections in infancy: Three cases and a review of the literature. Surg Neurol Int 1:34, 2010

9. Plauché WC: Subgaleal hematoma. A complication of instrumental delivery. JAMA 244:1597-1598, 1980

10. Roy HA, Magdum S: Sub-aponeurotic fluid collection in a neonate associated with fetal scalp electrode monitoring: a brief communication. Eur J Obstet Gynecol Reprod Biol 181:343-344, 2014

11. Schoberer A, Yagmur E, Boltshauser E, Korinth M, Niggemann P, Häusler M: Sub-aponeurotic fluid collections: a delayed-onset self-limiting cerebrospinal fluid fistula in young infants. Eur J Paediatr Neurol 12:401-403, 2008

12. Sorokin Y, Weintraub Z, Rothschild A, Abramovici H, Iancu TC: Cerebrospinal fluid leak in the neonate-complication of fetal scalp electrode monitoring. Case report and review of the literature. Isr J Med Sci 26:633-635, 1990

13. Turbeville DF, McCaffree MA: Fetal scalp electrode complications: cerebrospinal fluid leak. Obstet Gynecol 54:469470, 1979

14. Vaibhav A, Smith R, Millman G, Cooper J, Dwyer J: Subaponeurotic or subgaleal fluid collections in infancy: an unusual but distinct cause of scalp swelling in infancy. BMJ Case Rep 2010:bcr0420102915, 2010

15. Worthen M, Leonard TH, Blair TR, Gupta N: Experiences of parents caring for infants with rare scalp mass as identified through a disease-specific blog. J Am Board Fam Med 28:750-758, 2015

\section{Disclosures}

The authors report no conflict of interest concerning the materials or methods used in this study or the findings specified in this paper.

\section{Author Contributions}

Conception and design: Kulkarni, Wang. Acquisition of data: all authors. Analysis and interpretation of data: Kulkarni, Wang. Drafting the article: Kulkarni, Wang. Critically revising the article: Kulkarni, Wang. Reviewed submitted version of manuscript: all authors. Approved the final version of the manuscript on behalf of all authors: Kulkarni. Study supervision: Kulkarni, Drake.

\section{Correspondence}

Abhaya V. Kulkarni, Division of Neurosurgery, Department of Surgery, University of Toronto, 555 University Ave., Toronto, ON M5G 1X8, Canada. email: abhaya.kulkarni@ sickkids.ca. 